\title{
Influence of the chain length of surfactant in the modification of zeolites and clays. Removal of atrazine from water solutions
}

\section{Helen Paola Toledo-Jaldin, Alien Blanco-Flores, Víctor Sánchez-Mendieta \& Osnieski Martín-Hernández}

To cite this article: Helen Paola Toledo-Jaldin, Alien Blanco-Flores, Víctor Sánchez-Mendieta \& Osnieski Martín-Hernández (2017): Influence of the chain length of surfactant in the modification of zeolites and clays. Removal of atrazine from water solutions, Environmental Technology, DOI: 10.1080/09593330.2017.1365097

To link to this article: http://dx.doi.org/10.1080/09593330.2017.1365097

Accepted author version posted online: 07

Aug 2017.

Published online: 30 Aug 2017.

Submit your article to this journal $\pi$

山 Article views: 5

View related articles $₫$

View Crossmark data $\nearrow$ 


\title{
Influence of the chain length of surfactant in the modification of zeolites and clays. Removal of atrazine from water solutions
}

\author{
Helen Paola Toledo-Jaldin ${ }^{a}$, Alien Blanco-Flores ${ }^{b}$, Víctor Sánchez-Mendieta ${ }^{c}$ and Osnieski Martín-Hernández ${ }^{\mathrm{d}}$ \\ ${ }^{a}$ Facultad de Química, Universidad Autónoma del Estado de México, Toluca, Estado de México, México; bivisión de Mecánica, Tecnológico de \\ Estudios Superiores de Tianguistenco, Santiago Tianguistenco, Estado de México, México; ${ }^{C}$ Centro Conjunto de Investigación en Química \\ Sustentable UAEM-UNAM, Toluca, Estado de México, México; ${ }^{d}$ Síntesis y Formulaciones de Alta Tecnología S. A de C.V, Tlalnepantla, México
}

\section{ABSTRACT}

Removal potentials of a surfactant modified zeolite (SMZ) and clay (SMC) for atrazine adsorption were evaluated. Materials were modified with hexadecyl trimethyl ammonium bromide (HDTMA$\mathrm{Br}$ ) and benzyl octadecyl dimethyl ammonium (BODA) chloride considering the critical micellar concentration (CMC) of each one (0.94 and $0.041 \mathrm{meq} / \mathrm{L}$, respectively). The influence of the surfactant was analyzed in detail, particularly the formation of surfactant layers (complete or partial) connected with the length of the surfactant tail (16 and 18 methyl groups or number of carbons in the chain). Raw materials were characterized by XRD and Fourier transform infrared spectroscopy (FTIR), SMZ and SMC were analyzed by FTIR. Results obtained from kinetic adsorption experiments shown that equilibrium time is less for materials modified with HDTMA $(8 \mathrm{~h})$ than materials with BODA (10 and $12 \mathrm{~h})$. Materials modified with the largest chain surfactant (BODA) showed more resistance to atrazine masse transference. The chemisorption was presented in the adsorption mechanisms of atrazine and adsorbent materials. Based on the results of adsorption isotherms Langmuir isotherms showed the better correlation coefficients value. The $\mathrm{q}_{\max }$ is greater for materials modified with BODA $(0.9232$ and $4.2448 \mathrm{mg} / \mathrm{g})$ than for materials modified with HDTMA $(0.6731$ and $3.9121 \mathrm{mg} / \mathrm{g})$. Therefore, SMZ and SMC modified with the largest chain surfactant has more affinity for the pesticide. The removal process at high concentration of atrazine depends of the partition process but at lower concentration, it occurs not only by this process but also by absorption process.
ARTICLE HISTORY

Received 30 April 2017

Accepted 3 August 2017

KEYWORDS

Atrazine; partition-adsorption model; HDTMA; BODA surfactant; Surfactant Modified Zeolite (SMZ); Surfactant Modified Clay (SMC)

\section{Introduction}

The vital importance of agriculture is as well recognized as the usefulness of pesticides in mitigating disease-carrying pests [1] and weed control. However, pollution by pesticides is a problem due to its potential toxicity to animals, plants and humans. Because the aquatic environment is the ultimate recipient of the pollutants produced by natural and anthropogenic sources, the accumulation and persistence of pesticides in the aquatic environment constitutes a threat to biological life [2]. Due to regulatory authorities concern about this problem, more than 394 pesticides human health benchmark have been developed by the Environmental Protection Agency in order to determine potential health risk in drinking water or source water [3].

The pesticide atrazine is a herbicide which has been developed to avoid the growth of no wished vegetation in various crops. It is highly persistent in the environment due to its resistance to abiotic hydrolysis (stable at pHs 5,
7, and 9), its limited volatilization potential and is only moderately susceptible to aerobic biodegradation. Atrazine does not get adsorbed to soil particles strongly and therefore has a relatively high potential to contaminate ground and surface waters despite its moderate solubility in water $\left(33 \mathrm{mg} / \mathrm{L}\right.$ at $\left.20^{\circ} \mathrm{C}\right)$ [4]. Although it has been banned in the European market since 2004 and has been considered priority substances in the field of water policy since 2001 its occurrence and persistence in groundwater are of concern [5]. Atrazine quantities greater than permissible limits have been found in groundwater in China $(3.29 \mu \mathrm{g} / \mathrm{L})$, EUA $(88 \mu \mathrm{g} / \mathrm{L})$, Italy $(8.2 \mu \mathrm{g} / \mathrm{L})$ and Mexico $(21.26 \mu \mathrm{g} / \mathrm{L})$ [6]. For these reasons, the use of atrazine is highly controversial [7]. Many investigations focusing on its effect on rodents [8], arthropods [9], wide diversity of aquatic fauna $[10,11]$ and aquatic plants [12] showed the toxicity of atrazine in many different concentration above its upper limit. 
Since organic pollutants, such atrazine, are transferred to surrounding surface and groundwater [13], many researchers have been focused on removal methods such as biodegradation of atrazine by microbial consortium [14], ozonation [15], ultrasonic destruction [16], among others.

However, due to its high chemical and biological stability, most conventional water treatment techniques, except for adsorption, have low removal efficiency for atrazine from water [4]. Abu-Zreig et al. [17] determined that a mechanism to remove atrazine could be the adsorption of surfactants by soil constituent. Application of surfactants to soil in a concentration of $3000 \mathrm{mg} / \mathrm{L}$ can result in a significant increase of atrazine adsorption.

Bentonite is a clay mineral and maybe one of the most abundant clay rocks with exceptional adsorption properties. The main clay mineral present in bentonite is montmorillonite, which belongs to the smectite mineral group [18]. Structurally, in clay minerals the tetrahedral sheet is always combined with an octahedral sheet. A cation $\left(\mathrm{Al}^{3+}, \mathrm{Mg}^{2+}, \mathrm{Fe}^{2+}\right)$ is surrounded by six neighbors (oxygens or hydroxyls). Throughout the mineral, there is a tetrahedral/octahedral (TO) layered structure with tight packing between the layers [19]. Mordenite is widely used zeolite used as adsorbent for water purification. It is abundant in nature as a mineral with high purity, though some sources contain admixtures of iron oxides, mordenite and quartz [20]. On the other hand, zeolites are crystalline aluminosilicates with open 3D framework structures built of $\mathrm{SiO}_{4}$ and $\mathrm{AlO}_{3}$ tetrahedra linked to each other by sharing all the oxygen atoms to form regular intra-crystalline cavities and channels of molecular dimensions [21].

Zeolites and clays have permanent negative charges, which are compensated with the named 'exchangeable cations'. These exchangeable cations are located and available for interchange in the interlayer space of bentonite sheets [18] and on the surface of zeolites [21]. Therefore, clays possess fairly a high cation exchange capacity (CEC) [22].

Although clay and zeolites were used widely to remove inorganic pollutants from wastewaters $[23,24]$ they showed insignificant applicability in the treatment of several organic pollutants having non- or low-polarity. However, some modifications could be done on the materials to provide them with specific characteristics. Surfactants are high-molecular-weight quaternary ammonium salts, which dissolve in water and hydrolyze to an inorganic ion $(-\mathrm{Br}$ or $-\mathrm{Cl})$ and an organic cation, which is exchange for the clay and zeolite exchangeable cations during the modification process. The surfactant concentration in the modified solution is relevant because a low concentration may be formed a partial layer of surfactant, while at high concentrations the orientation of the organic molecules may not be adequate for simple or double layer formation [25]. Depending on the layers formation, the modified materials possess an enhanced organophilicity and this, perhaps, be effective in attenuation of several organic pollutants from aqueous solutions [26]. Neutral species, such as atrazine, can partition into the hydrophobic layer formed after surfactant modification [27].

Subsequent researchers reported that the lyophilic tails from cations of long-chain quaternary ammonium salts, previously retained on the clay or zeolites, lead to the adsorption of atrazine increasing its capacity more than $50 \%[28,29]$. Moreover, Xie et al. [30] showed that the amount of surfactant loaded increased (coverage from 105 to 208) with increasing chain length (from $1 C$ to $22 \mathrm{C}$ ) and at the same time the organic substance adsorption increment (more than 80\%). In addition, they noted that long chain length, high surfactant coverage and ordered chain conformation are the influential factors for the adsorption of organic pollutants.

In this work, a Mexican clay and a Cuban zeolite with relatively high CEC were selected as principal material. The SMC and SMZ were prepared with two different long chains surfactant loadings (hexadecyl trimethyl ammonium (HDTMA) and BODA) with 16 and 18 methyl groups. In this study, the surfactants' retained amount was followed to investigate their influence on atrazine removal, and the effect of the surfactant chain length was evaluated. Materials after and before demodification process were characterized by Fourier transform infrared spectroscopy (FTIR) and scanning electron microscopy (SEM). Finally, the adsorption capacity of these materials toward atrazine was investigated through a series of batch experiments under experimental conditions.

\section{Materials and methods}

\subsection{Materials}

The zeolitic material used in this work was: zeolitic tuff from Palmarito del Cauto, Santiago, Cuba $\left(Z_{1}\right)$ and a commercial bentonite clay $\left(C_{B}\right)$ purchased from SigmaAldrich, México. The total CEC of $C_{B}$ was $0.82 \mathrm{meq} / \mathrm{g}$. All materials were grinned, sieved and characterized.

Atrazine standard, used in this research, was supplied by SIFACTEC S.A. de C.V. Working solutions were prepared by diluting the stock solutions first with methanol and then with distilled water. The standard stock was stored at $277 \mathrm{~K}$ and used to prepare dilute solutions.

The cationic surfactant, HDTMA-Br $\left(\mathrm{C}_{19} \mathrm{H}_{42} \mathrm{NBr}\right.$, FW: $364.46 \mathrm{~mol} / \mathrm{g}$ ) with a purity of $99 \%$, was purchased from Sigma-Aldrich and the benzyl octadecyl dimethyl ammonium chloride (BODA-Cl, $\mathrm{C}_{27} \mathrm{H}_{50} \mathrm{NCl}$, FW: 
$424.15 \mathrm{~mol} / \mathrm{g}$ ) was supplied by Organo Síntesis S.A. de C.V. The critical micelle concentration (CMC) of HDTMA-Br is $0.94 \mathrm{meq} / \mathrm{L}$, as estimated by conductivity measurements of aqueous HDTMA-Br solutions at different concentrations [31]. The CMC of BODA-Cl is $0.041 \mathrm{meq} / \mathrm{L}$ estimated by Lien [32].

\subsection{Methods}

\subsubsection{Preparation materials}

Zeolite material $Z_{1}$ was treated with $\mathrm{NaCl}$ solutions to obtain a homoionic material. $50 \mathrm{~g}$ of $Z_{1}$ was introduced in a batch type treatment with $500 \mathrm{~mL}$ of $0.1 \mathrm{M} \mathrm{NaCl}$ solution in reflux for $3 \mathrm{~h}$. Then, the phases were separated and the zeolites were once more placed in a reflux in the same conditions with fresh solutions. The material was washed until the complete elimination of chloride was confirmed by the $\mathrm{AgNO}_{3}$ test.

The external cation exchange capacity (ECEC) of $Z_{1}$ were determined by the adsorption of methylene blue (MB). The ECEC value was measured by the retention of $\mathrm{MB}$, a cationic dye, which is too large to intercalate into the internal pores of zeolite, and is known to form monolayer coverage on the surface [33]. $20 \mathrm{~mL}$ of the aqueous solutions of MB (from 5 to $200 \mathrm{mg} / \mathrm{L}$ ) were added to $0.1 \mathrm{~g}$ of $Z_{1}$ samples. The tubes were then shaken for $24 \mathrm{~h}$ at $298 \mathrm{~K}$. After that, suspensions were centrifuged and supernatants were determined by a spectrophotometer (UV-VIS Perkin Elmer Lambda 10) at $668 \mathrm{~nm}$ directly for $M B$ [30]. The maximum adsorption capacity of $Z_{1}$ was calculated and associated with the external CEC.

The material $C_{B}$ and $Z_{1}$ were modified with both surfactants, each one with a different surfactant concentration because CEC values and surfactant CMC are unlike. Concentrations for $C_{B}$ were established above the CMC of each surfactant. The mass of surfactant was compared with the CEC of each material and was calculated by the following equation:

$$
\frac{n_{\text {sol }}}{m_{\mathrm{c}}}=2 \mathrm{CEC} \text {. }
$$

Concentrations for $Z_{1}$ modifications were equal to the CMC. The amount of surfactant was calculated with the following equation:

$$
\frac{n_{\text {sol }}}{m_{z}}=\mathrm{CEC},
$$

where $n_{\text {sol }}$ is the number of moles in terms of miliequivalents (meq) of surfactant calculated from the concentration $(\mathrm{mmol} / \mathrm{L})$ and volume $(\mathrm{mL})$ of the solution, $m_{\mathrm{c}}$ is the mass ( $\mathrm{g}$ ) of clay and $m_{\mathrm{z}}$ is the mass ( $\mathrm{g}$ ) of zeolite.

This modification was made by considering previous works [34] and applying the same time, temperature and agitation conditions for $C_{B}$ and $Z_{1}\left(48 \mathrm{~h}, 30^{\circ} \mathrm{C}\right.$ and $100 \mathrm{rpm}$ ). Materials $C_{B}$ and $Z_{1}$ modified with HDTMA were labeled as $C_{B}$-HDTMA and $Z_{1}$-HDTMA, while $C_{B}$ and $Z_{1}$ modified with BODA were labeled as $C_{B}-B O D A$ and, $Z_{1}-B O D A$, respectively.

After the modification, $Z_{1}$-HDTMA, $Z_{1}-B O D A, C_{B}-$ HDTMA and $C_{B}$-BODA were separated from the solution by filtration and washed with deionized water to remove any surfactant excess and a negative bromide and chloride test was performed [35].

The amount of surfactant retained in each material was estimated using the concentration of carbon in the modified materials. The carbon was estimated using a CHNS-O analyzer, CE-Instrument model EA-1110. The concentration of surfactants $C_{(s)}$ in every material (in $\mathrm{mol} / \mathrm{g}$ ) was calculated from the following equation:

$$
C_{(\mathrm{s})}=\frac{C_{\mathrm{c}}}{\left(n_{\mathrm{c}} \cdot M_{\mathrm{c}}\right)},
$$

where $C_{\mathrm{c}}$ is the carbon content in the sample in weight, $n_{c}$ the number of carbon atoms (in HDTMA: $n_{c}=19$, in BODA: $\left.n_{\mathrm{c}}=27\right)$ and $M_{\mathrm{c}}$ the molecular mass of carbon $(\mathrm{mol} / \mathrm{g})[36]$.

\subsubsection{Characterization materials}

$Z_{1}$ and $C_{B}$ were characterized by $X$-ray diffraction (XRD) for phase identification using a Bruker D8 advance instrument with $\mathrm{Cu}$ target with secondly monochromator $30 \mathrm{kV}, 25 \mathrm{~mA}$.

The infrared spectra (IR) in the $400-4000 \mathrm{~cm}^{-1}$ range with a resolution of $4 \mathrm{~cm}^{-1}$ and 32 scans sweep were recorded for the adsorbents at room temperature, using a Bruker Tensor 27 FTIR attenuated total reflection (ATR). The samples did not require previous preparation due to the ATR attachment.

\subsubsection{Adsorption kinetics}

Kinetic experiments were performed in a batch mode using $100 \mathrm{mg}$ of adsorbents and $10 \mathrm{~mL}$ of atrazine solution with concentration of $5 \mathrm{mg} / \mathrm{L}$ at constant temperature $298 \mathrm{~K}$ and the $\mathrm{pH}$-value was close to 6-7 without any adjustment. The glass flasks were shaken at $100 \mathrm{rpm}$. One sample was prepared without any adsorbent to accurately determine the initial concentration of the solution. Samples were collected at different time intervals ( $15 \mathrm{~min}-24 \mathrm{~h}$ ) in order to determine the optimal contact time. The collected samples were separated, zeolite was decanted and bentonite samples were centrifuged for $5 \mathrm{~min}$ in a HETTICH EBA-20 centrifuge at $4000 \mathrm{rpm}$ and aqueous solutions were analyzed on a UVVis spectrophotometer Perkin Elmer Lambda 35 at $222 \mathrm{~nm}$. 
To illustrate the adsorption process and provide insights into possible adsorption process, a pseudofirst-order, pseudo-second-order and Intraparticle Diffusion models $[37,38]$ were used to fit the experimental data. Regression coefficients of these models were calculated to determine the best fitted one. The applied software used for this purpose was ORIGIN 8.1 ${ }^{\mathrm{TM}}$.

\subsubsection{Adsorption isotherms}

The equilibrium adsorption isotherms were conducted by adding a constant dose of $Z_{1}-B O D A, Z_{1}$-HDTMA, $C_{B^{-}}$ BODA and $C_{B}$-HDTMA (100 mg) into $10 \mathrm{~mL}$ of atrazine solutions with initial concentrations from 2 to $50 \mathrm{mg} / \mathrm{L}$ at equilibrium time. The $\mathrm{pH}$ of the mixture was 7 without any further adjustment during experiments. The mixture was maintained at a setting temperature of $298 \mathrm{~K}$ and stirred at $100 \mathrm{rpm}$.

Adsorption isotherms models provide practical information such as the capacity of the adsorbent and inferences on possible mechanisms of the adsorption processes [39]. Two adsorption isotherms models were applied to describe the results, the nonlinear form of Langmuir and Freundlich [37]. The same software of kinetics data was applied.

Since it is possible to find two types of interactions (adsorption and partition) between organic compounds and SMC or SMZ, adsorption/partition model was applied [40].

\section{Results and discussion}

\subsection{Preparation materials}

The external CEC of $Z_{1}$ was found to be $0.23 \mathrm{meq} / \mathrm{g}$. It has been recognized that the length of the surfactant hydrocarbon chain plays a prominent role in determining the critical concentration for the formation of micelles (CMC). The longer the carbon chain length, the greater the hydrophobic interaction between alkyl chains, and the lower the value of the CMC [30]. For this reason, the CMC of surfactants were taking into account, in the present work, to modify every material and not only the CEC and ECEC as was reported before by other authors such as Malekian et al. [41], Jarraya et al. [42] and Zheng et al. [43].

It was found that $C_{(\mathrm{s})}$ for $Z_{1}-B O D A, Z_{1}-$ HDTMA, $C_{B}$ BODA and $C_{B}$-HDTMA was 0.21, 0.19, 1.61 and $1.45 \mathrm{mmol} / \mathrm{g}$. The coverage of surfactant was then estimated by comparing the number of loaded surfactant with CEC, ECEC and the solution concentration $\left(C_{\text {sol }}\right)$ related to de CMC. A graphical representation of surfactant modified solutions and its presumed disposition onto and inside the materials was plotted in Power
Point considering the surface for zeolite and a laminar disposal for bentonite (Figure 1(a-d)).

For zeolite modification, the $C_{\text {sol }}$ does not allow the formation of micelles in the solution (Figure 1(a)). The carbon determination points out the presence of an incomplete monolayer (Figure 1(b)); however, previously studies reported the formation of a complete monolayer $[41,44]$.

Hoseini and Nezamzadeh-Ejhieh suggest that after ion exchanging of the surfactant organic cations via ammonium head group with ion exchange sites in the material, the hydrophobic forces of the chain adsorb other surfactant cations onto the adsorbed first layer. In this condition, a semi double layer or double layer could be formed [45]. Since it has been recognized that above the CMC the formation of micelles is possible, the $C_{\text {sol }}$ used in bentonite modification allows the formation of micelles [46] as can be seen in Figure 1(c). In this case, the established surfactant amount is close to $200 \%$ of CEC, assuming the formation of a semi double layer (Figure $1(\mathrm{~d})$ ). This result is consistent with previous works [34].

It is clear that the coverage of materials depended greatly on the kind of surfactant [47] and that the coverage increased with increasing surfactant chain length as reported by Xie et al. [30]. On the other hand, despite the presence of aromatic ring in the BODA, the retained quantity of this surfactant is grater and this is in agreement with Majdan [48], who modified a sodium bentonite with HDTMA and BODA, among other surfactants.

The results for $C_{B}-B O D A$ and $C_{B}$-HDTMA indicate that longer chain length results in higher surfactant adsorption in the second layer. Similar results have recently been observed by Li and Gallus [49], who compared the adsorption of dodecyltrimethylammonium (C12) and hexadecyl trimethylammonium (C16) onto kaolinite.

\subsection{Characterization materials}

According to XRD spectrum for untreated zeolite, the material contains mordenite, clinoptilolite and heulandite (PDF 00-029-1257; 00-047-1870; 00-019-0211, respectively). The XRD pattern of raw clay had good agreement to PDF- 00-003-0010 and 00-003-0015, correspond to montmorillonite (bentonite) and to PDF-01083-0539 linked to quartz.

In order to identify the surfactant loading on/in the zeolites, the FTIR spectra of HDTMA and BODA were taken and compared with materials after and before the modifications. The FTIR spectra of the BODA, $Z_{1}$ and the prepared $Z_{1}-B O D A$ are shown in Figure 2 . The presence of peaks around 2917 and $2850 \mathrm{~cm}^{-1}$ in BODA spectrum correspond to asymmetric and 
a)

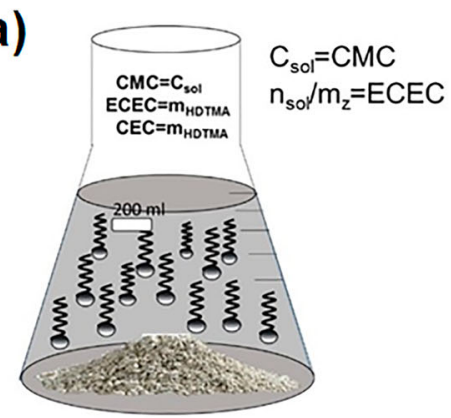

c)

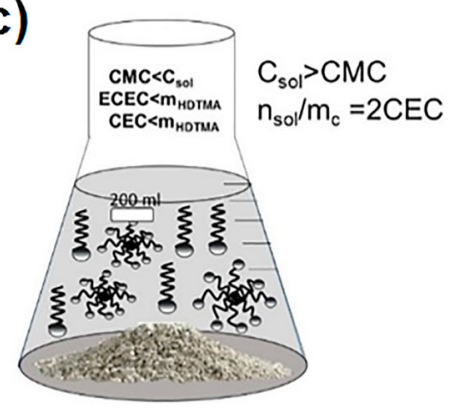

b)

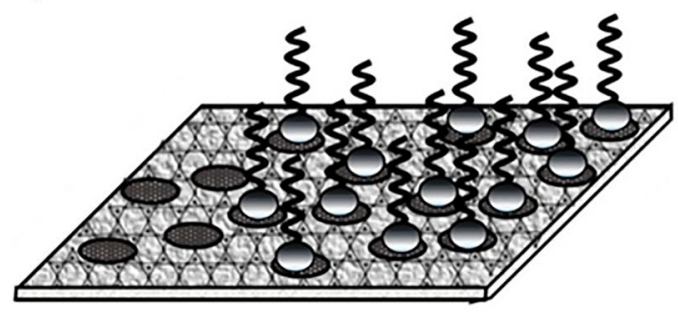

d)

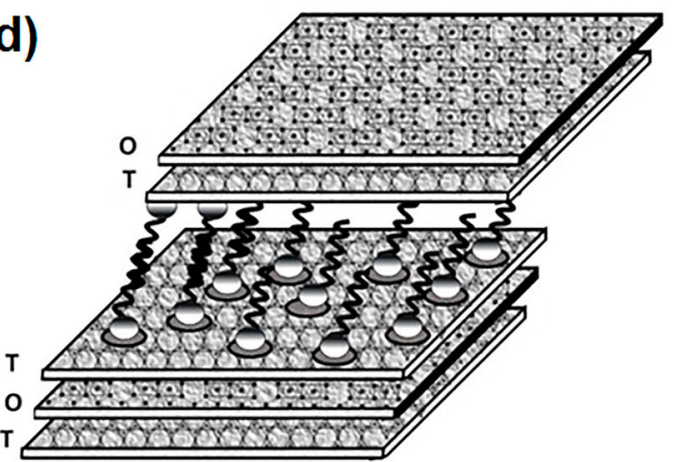

Figure 1. (a) Modified solution for zeolites equal CMC of surfactants, (b) Possible arrangement of surfactant onto zeolites forming an incomplete monolayer, (c) Modified solution for clay above the CMC of surfactant and (d) Possible interlayer arrangement of surfactant in clay material forming a patchy bilayer.

symmetric stretching vibrations of $\mathrm{C}-\mathrm{H}$ in the surfactant, respectively. Absorption bands at around 2913 and $2849 \mathrm{~cm}^{-1}$ in $Z_{1}$-BODA are not present in $Z_{1}$ zeolite spectrum, confirming the loading of BODA onto synthesized zeolite. The band at 1468 and $728 \mathrm{~cm}^{-1}$ correspond to the methylene scissoring mode and methylene rocking mode [50]. The band at $1468 \mathrm{~cm}^{-1}$ does not distinguish clearly on the $Z_{1}-B O D A$ spectra; however the $728 \mathrm{~cm}^{-1}$ band appear at $726 \mathrm{~cm}^{-1}$. Bands at 3450 and $1635 \mathrm{~cm}^{-1}$ in IR spectrum of raw zeolite $Z_{1}$ refer to water molecules associated with $\mathrm{Na}$ and $\mathrm{Ca}$ in the channels and cages of the zeolite structure [51]. All zeolites

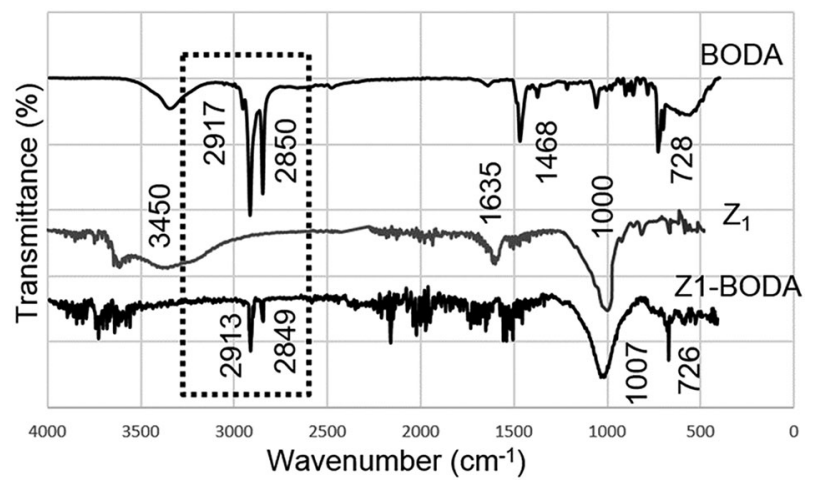

Figure 2. FTIR spectra of the BODA, $Z_{1}$ and the prepared $\mathrm{Z}_{1}$-BODA. revealed a distinct band between 1000 and $1007 \mathrm{~cm}^{-1}$, resulting from $\mathrm{Si}-\mathrm{O}$ stretching vibrations [36]. This last band has not significant changes before and after the modification, showing that the main structure of the zeolite and clay remained the same.

In case of pure HDTMA, two principal bands appear at 2852 and $2915 \mathrm{~cm}^{-1}$ (Figure 3). According to Barczyk et al. [52], they are associated with asymmetric and symmetric stretching vibrations of $\mathrm{CH}_{2}$ groups. In the spectra of clay treated with HDTMA, these bands are shifted towards lower wavenumbers to 2849 and $2913 \mathrm{~cm}^{-1}$.

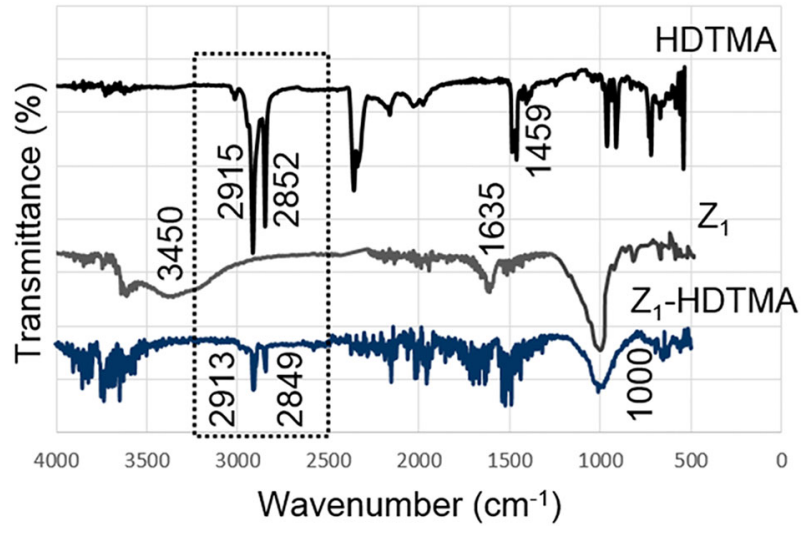

Figure 3. FTIR spectra of the HDTMA, $Z_{1}$ and the prepared $\mathrm{Z}_{1}$-HDTMA. 


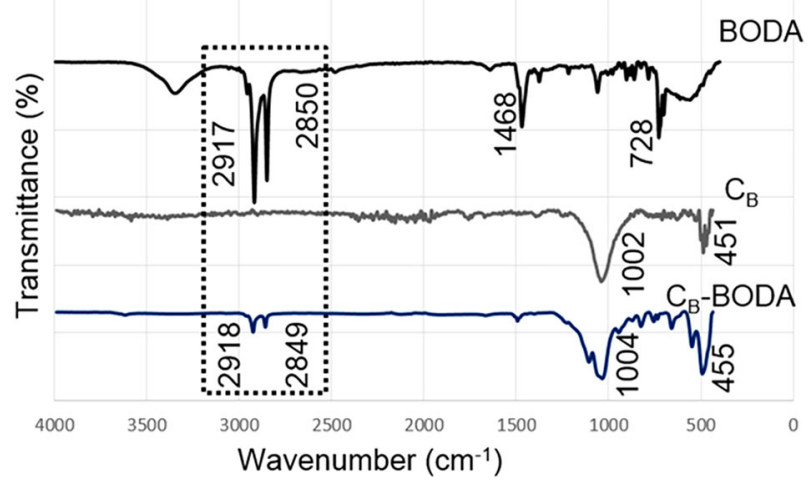

Figure 4. FTIR spectra of the BODA, $C_{B}$ and the prepared $\mathrm{C}_{B}$-BODA.

Sharafzadeh and Nezamzadeh-Ejhieh [53] verified the loading of HDTMA by the presence of characteristics bands around 2800 and $2900 \mathrm{~cm}^{-1}$. Two close bands were observed at 1461 and $1463 \mathrm{~cm}^{-1}$ related to scissoring vibrations of methylene groups. The asymmetrical vibration of $(\mathrm{Si}-\mathrm{O})$ appeared at $1000 \mathrm{~cm}^{-1}$ for $\mathrm{Z}_{1}$ and $\mathrm{Z}_{1}$-HDTMA [37].

Two bands around 2918 and $2849 \mathrm{~cm}^{-1}$, assigned to the asymmetric and symmetric stretching vibrations of $\mathrm{C}-\mathrm{H}$ in the surfactant, appear in $\mathrm{C}_{\mathrm{B}}-\mathrm{BODA}$ pointing its presence in the modified material (Figure 4). A weak band in $1470 \mathrm{~cm}^{-1}$ confirmed the presence of methylene groups shifted from $1468 \mathrm{~cm}^{-1}$ in BODA spectra. The presence of an asymmetric stretching mode of $\mathrm{Si}-\mathrm{O}-\mathrm{Si}$ in original clays and SMC was suggested by the absorption bands at 1002 and $1004 \mathrm{~cm}^{-1}$, respectively. The asymmetric and symmetric bending modes of $\mathrm{Si}-\mathrm{O}$ are observed at 451 and $455 \mathrm{~cm}^{-1}$ for both the original clays and modified clays.

Figure 5 clearly indicates the modification of $C_{B}$-HDTMA by the presence of the two principal bands at 2848 and $2912 \mathrm{~cm}^{-1}$.

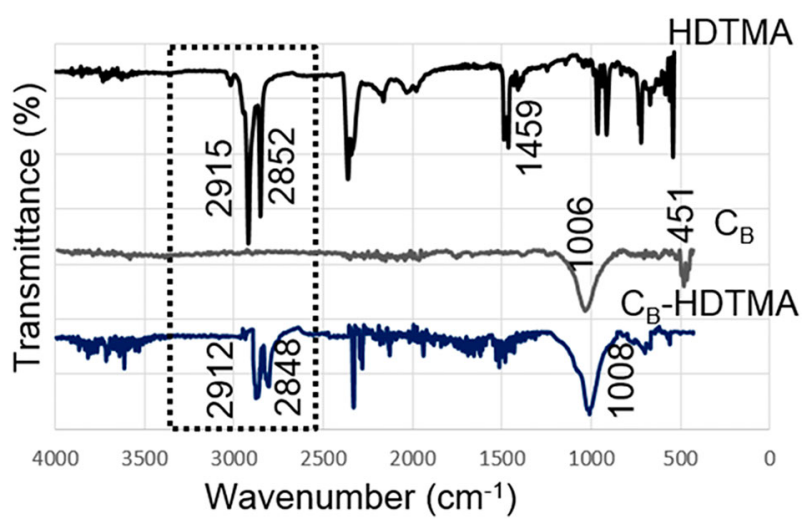

Figure 5. FTIR spectra of the HDTMA, $C_{B}$ and the prepared $C_{B}$-HDTMA.

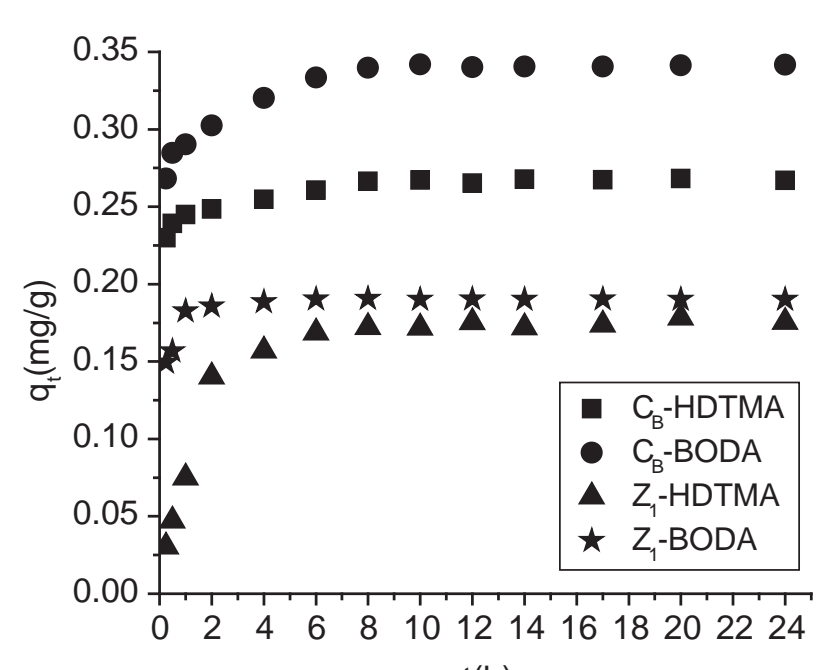

$\mathrm{t}(\mathrm{h})$

Figure 6. Adsorption kinetic of atrazine onto SMZ and SMC: $10 \mathrm{ml}-5 \mathrm{mg} / \mathrm{L}$ atrazine: $100 \mathrm{mg}$ sorbent: $298 \mathrm{~K}, \mathrm{pH}$ not adjusted.

\subsection{Kinetics}

The adsorption kinetics were studied to determine the time required for the system to reach equilibrium. The results given in Figure 6 showed that the adsorption of atrazine has gradually increased with contact time in case of $Z_{1}$-HDTMA. On the contrary, for the other three modified materials $\left(Z_{1}-B O D A, C_{B}-H D T M A, C_{B}-B O D A\right)$ the adsorption increased rapidly in the first hour. The removal of atrazine by $Z_{1}$-HDTMA reached equilibrium at round $8 \mathrm{~h}$. The $Z_{1}$-BODA reached its maximum adsorption at $12 \mathrm{~h}$. In case of $C_{B}$-HDTMA, there is a rapid adsorption from 0 to $0.25 \mathrm{~h}$, and equilibrium was observed at $8 \mathrm{~h}$. Finally, $C_{B}-B O D A$ reached the equilibrium at round $10 \mathrm{~h}$ (Figure 6).

According to Zheng et al. [43], the fast removal rate implies strong interaction between the modified materials and the atrazine. Based on these results, it is clear that equilibrium time is less for materials modified with HDTMA than materials with BODA. This could be a consequence of a diffusive process between the adsorbed and the adsorbent material. The chemical structure of surfactant BODA might hinder the superficial diffusion of the adsorbed slowing down its flow more than the HDTMA surfactant. This was demonstrated by applying the intraparticle diffusion model [54]. A multi linear graphic for every material showed three linear zones (graphic it not showed) pointing out the presence of two different diffusive processes: the diffusion of the adsorbed through the boundary layer of the particle (I-Zone) and the intraparticle diffusion (II-Zone). Materials modified with the largest chain surfactant (BODA) showed more resistance to atrazine masse transference. This last result complement results obtained for the 
Table 1. Intraparticle diffusion model parameters for the adsorption atrazine and organomaterials.

\begin{tabular}{lcccc}
\hline Parameters & $Z_{1}$-HDTMA & $Z_{1}$-BODA & $C_{B}$-HDTMA & $C_{B}-$ BODA \\
\hline $\mathrm{k}_{\text {id }}\left(\mathrm{mg} /\left(\mathrm{gh}^{0.5}\right)\right.$ & 0.023 & 0.005 & 0.012 & 0.025 \\
$\mathrm{C}(\mathrm{mg} / \mathrm{g})$ & 0.109 & 0.178 & 0.232 & 0.266 \\
Amount of linear zones & 3 & 3 & 3 & 3 \\
\hline
\end{tabular}

boundary layer of the particle got from the model. $Z_{1}-B O D A$ and $C_{B}-B O D A$ have the higher value of boundary layer parameter (Table 1 ).

The pseudo-first-order and pseudo-second-order kinetics models were applied to the experimental data based on the following described equations [55]:

The pseudo-first-order model (Lagergren): In this model, which is commonly used for homogeneous sorbents and physical sorption, the sorption rate is proportional to the solute concentration. If the sorption behavior is pseudofirst-order, then the experimental results could be adjusted to the following equation:

$$
q_{t}=q_{\mathrm{e}}\left(1-e^{K_{\llcorner} t}\right),
$$

where $q_{\mathrm{e}}$ and $q_{t}$ are the amounts of atrazine adsorbed $(\mathrm{mg} / \mathrm{g})$ in the equilibrium and at time $t(\mathrm{~min})$, respectively, and $K_{\mathrm{L}}\left(\mathrm{min}^{-1}\right)$ is the adsorption constant of Lagergren.

The pseudo-second-order model: The pseudo-secondorder model is based on the assumption that the ratelimiting step may be chemisorption, involving valence forces through the sharing or exchange of electrons between adsorbent and adsorbate. This model can be represented in the following equation:

$$
q_{t}=\frac{q_{\mathrm{e}}^{2} k t}{1+q_{\mathrm{e}} k t}
$$

where $q_{t}$ and $q_{\mathrm{e}}$ are the amounts adsorbed at time $t$ and at equilibrium $(\mathrm{mg} / \mathrm{g})$, respectively, and $k$ is the pseudosecond-order rate constant for the sorption process ( $\mathrm{g} / \mathrm{mg} \cdot \mathrm{min})$.

The parameters of both models are summarized in Table 2. The pseudo-second-order kinetic model fitted better than the pseudo-first-order model, which is similar to previously published results [56] and [57]. Furthermore, the $\mathrm{q}_{\mathrm{e}}$ calculated by the pseudo-second-order

Table 2. Kinetic parameters for the adsorption atrazine and

\begin{tabular}{|c|c|c|c|c|c|c|}
\hline \multirow[b]{2}{*}{ Sample } & \multicolumn{3}{|c|}{ Pseudo-first-order } & \multicolumn{3}{|c|}{ Pseudo-second-order } \\
\hline & $\begin{array}{c}K_{1} \\
\mathrm{~h}^{-1}\end{array}$ & $\begin{array}{c}q_{\mathrm{e}} \\
(\mathrm{mg} / \mathrm{g})\end{array}$ & $R^{2}$ & $\begin{array}{c}K_{2} \\
\mathrm{~h}^{-1}\end{array}$ & $\begin{array}{c}q_{\mathrm{e}} \\
(\mathrm{mg} / \mathrm{g})\end{array}$ & $R^{2}$ \\
\hline$Z_{1}$-HDTMA & 0.67 & 0.17 & 0.9696 & 4.54 & 0.19 & 0.9898 \\
\hline$Z_{1}-B O D A$ & 5.41 & 0.19 & 0.7506 & 63.53 & 0.19 & 0.9412 \\
\hline$C_{B}-$ HDTMA & 8.00 & 0.26 & 0.4433 & 82.92 & 0.26 & 0.9063 \\
\hline $\mathrm{C}_{\mathrm{B}}-\mathrm{BODA}$ & 5.92 & 0.33 & 0.4538 & 35.93 & 0.34 & 0.9055 \\
\hline
\end{tabular}
organomaterials. model was closer to the values that were experimentally observed. This indicated that chemisorption was presented in the adsorption mechanisms of atrazine and adsorbent materials.

\subsection{Adsorption isotherms}

Based on the parameters derived from the adsorption isotherm models, it is possible to analyze materials surface property and maximum adsorption capacity $\left(q_{\max }\right)$ of each material [58]. The Langmuir isotherm is mainly applied to monolayer adsorption while the Freundlich isotherm is widely employed for adsorption surfaces with non-uniform energy distribution [59]. In this study, the Langmuir and Freundlich isotherm models were applied to analyze the mechanism of adsorption system between atrazine, SMZ and SMC. They are described below:

The Langmuir adsorption isotherm is

$$
q_{\mathrm{e}}=\frac{q_{\max } b C_{\mathrm{e}}}{1+b C_{\mathrm{e}}}
$$

where $q_{\mathrm{e}}$ is the amount of atrazine adsorbed per unit weight of adsorbent $(\mathrm{mg} / \mathrm{g}), q_{\max }$ is the amount of atrazine adsorbed per unit weight of adsorbent in forming a complete monolayer on the surface $(\mathrm{mg} / \mathrm{g}), C_{e}$ is the concentration of atrazine in the solution at equilibrium (mg/L) and $b$ is the constant related to the energy or net enthalpy of adsorption [55].

The mathematical representation of Freundlich equation is

$$
q_{\mathrm{e}}=K_{\mathrm{F}} C_{\mathrm{e}}^{1 / n},
$$

where $q_{\mathrm{e}}$ is the amount of atrazine adsorbed per unit weight of adsorbent $(\mathrm{mg} / \mathrm{g}), C_{\mathrm{e}}$ is the equilibrium concentration of atrazine in the solution ( $\mathrm{mg} / \mathrm{L}), K_{\mathrm{F}}$ is the equilibrium constant indicative of adsorption capacity and $n$ is the adsorption equilibrium constant whose reciprocal is indicative of the heterogeneity of surface sorbent. This model assumes surface heterogeneity and exponential distribution of active sites and provides an empirical relationship between the adsorption capacity and equilibrium constant of the adsorbent [55].

Based on the results of adsorption isotherms, Langmuir isotherms showed the better correlation coefficients value (Table 3 ). The $q_{\max }$ is greater for materials modified with BODA than for materials modified with HDTMA. It suggested that chain length caused an increase in the ability for the removal of atrazine, because the longer chain surfactant has more active groups, which enhance the adsorption of the pesticide.

It was observed than the materials modified with the largest chain surfactant has more affinity for the 
Table 3. Adsorption isotherms of atrazine on organomaterials.

\begin{tabular}{|c|c|c|c|c|c|c|}
\hline \multirow[b]{2}{*}{ Sample } & \multicolumn{3}{|c|}{ Langmuir } & \multicolumn{3}{|c|}{ Freundlich } \\
\hline & $\begin{array}{c}K_{\mathrm{L}} \\
(\mathrm{L} / \mathrm{mg})\end{array}$ & $\begin{array}{c}q_{\max } \\
(\mathrm{mg} / \mathrm{g})\end{array}$ & $R^{2}$ & $\begin{array}{c}K_{f} \\
(\mathrm{~L} / \mathrm{mg})\end{array}$ & $\begin{array}{c}1 / n \\
(\mathrm{mg} / \mathrm{g})\end{array}$ & $R^{2}$ \\
\hline $\mathrm{Z}_{1}$-HDTMA & 0.0388 & 0.6731 & 0.9501 & 0.0462 & 0.59 & 0.9052 \\
\hline$Z_{1}-B O D A$ & 0.0850 & 0.92 & 0.90 & 24 & 0. & 0.7903 \\
\hline$C_{B}-$ HDTMA & 0.0256 & 3.9121 & 0.9539 & 0.1468 & 0.74 & 0.9263 \\
\hline$C_{B}-B O D A$ & 0.0657 & 4.2448 & 0.9686 & 0.3456 & 0.59 & 0.9144 \\
\hline
\end{tabular}

pesticide (Figure 7). According to Xie [30], the influence of chain length on adsorption of organic solutes could be interpreted by the fact that longer chain brings about higher amount of loaded surfactant, more number of positive charge carried by surfactant, and create greater hydrophobicity of organic pseudophase produced by the alkyl carbon chain. The higher amount of loaded surfactant in $C_{B}$-HDTMA and $C_{B^{-}}$ BODA was stated previously.

The adsorption capacity of materials used in this research was compared with other reported on the literature (Table 4). Some greater values were found for clays with similar CEC $(0.81 \mathrm{meq} / \mathrm{g})$; however, the characteristics of the applied surfactant were different [60]. In case of [57] and [61] the synthetic zeolite and the activated carbon exhibit a greater CEC and surface area, respectively, compared to our materials, whereby the adsorption capacity is greater; however, the synthesis is more complex or requires more energy. Nevertheless, the capacity from this work materials are major than for acid-activated zeolites [62], silica [63] and bark of Eucalyptus tereticornis L. [64].

Due to the non-polar characteristics of atrazine and modified materials, it is possible to find two types of interactions between the adsorbate, SMZ and SMC, i.e. adsorption and partition [40,65]. The adsorption is the retention of a chemical specie on the active sites of the solid (adsorbent material), which is the stationary phase. This retention could be a physisorption or a<smiles>CCCCCC</smiles>

HDTMA

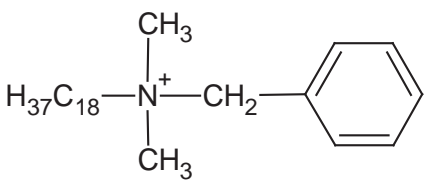

BODA

Figure 7. Chemical structure of HDTMA and BODA surfactants.
Table 4. Adsorption capacities of atrazine compared with different materials.

\begin{tabular}{cllc}
\hline Year & References & \multicolumn{1}{c}{ Material } & $q_{\max }(\mathrm{mg} / \mathrm{g})$ \\
\hline 2006 & {$[60]$} & Melamine-based organoclay & 6.00 \\
2011 & {$[57]$} & Synthetic modified zeolite & 11.86 \\
2015 & {$[61]$} & Sludge-based activated carbon & 45.49 \\
2010 & {$[62]$} & Acid-activated zeolite-rich tuffs & 1.10 \\
2011 & {$[63]$} & Silica & 0.42 \\
2016 & {$[64]$} & Bark of Eucalyptus & 0.94 \\
2017 & This work & C $_{B}$-HDTMA & 3.91 \\
2017 & This work & C $_{B}$-BODA & 4.24 \\
2017 & This work & Z $_{1}$-HDTMA & 0.67 \\
2017 & This work & Z $_{1}$-BODA & 0.92 \\
\hline
\end{tabular}

chemisorption. Furthermore, the partition is a phenomenon that takes place between a liquid phase adsorbed on a solid support and a mobile phase. The liquid phase covering the material is the stationary phase where the partition process takes place [66].

In our case, we established the contribution of adsorption and partition from the total sorption process by the adsorption/partition model. According to this model, the total sorption amount $\left(Q_{T}\right)$ of atrazine can be defined as

$$
Q_{T}=Q_{A}+Q_{P},
$$

where $Q_{A}$ is the sorption amount contribution by adsorption and $Q_{P}$ is the adsorption amount contribution by partition. The sorption caused by partition to the total amount of sorption can be calculated as follows:

$$
Q_{\mathrm{p}}=K_{\mathrm{oc}} \cdot f_{\mathrm{oc}} \cdot C_{\mathrm{e}},
$$

where $K_{\mathrm{oc}}$ is the organic carbon distribution coefficient and $f_{\mathrm{oc}}$ is the organic carbon fraction of the sorbent and $C_{e}$ is the equilibrium aqueous concentrations of the solute (mg/l). According to Batu [67], $K_{\text {oc }}$ for s-atrazines can be calculated as

$$
\operatorname{LogK}_{\mathrm{oc}}=0.94 \mathrm{~K}_{\mathrm{ow}}+0.02 \text {, }
$$

where $\log K_{\text {ow }}$ is the octanol-water partition constant, 2.69 for atrazine [68]. The regression of the overall data may be described as

$$
Q_{\mathrm{T}}=a \cdot \ln C_{\mathrm{e}}+b,
$$

where $a$ and $b$ are the fitted parameters. From Equations (8), (9) and (11) the sorption amount due to adsorption mechanism can be deduced as follows:

$$
Q_{\mathrm{A}}=\mathrm{a} \cdot \ln C_{\mathrm{e}}+b-K_{\mathrm{oc}} \cdot f_{\mathrm{oc}} \cdot C_{\mathrm{e}} .
$$

A plot of $Q_{T}, Q_{A}$ and $Q_{P}$ against $C_{e}$ for each material are shown in Figure 8 and these contributions can be calculated by functions described in Table 5 . As can be seen, partition process increases linearly with the increasing of concentrations while adsorption process showed a 

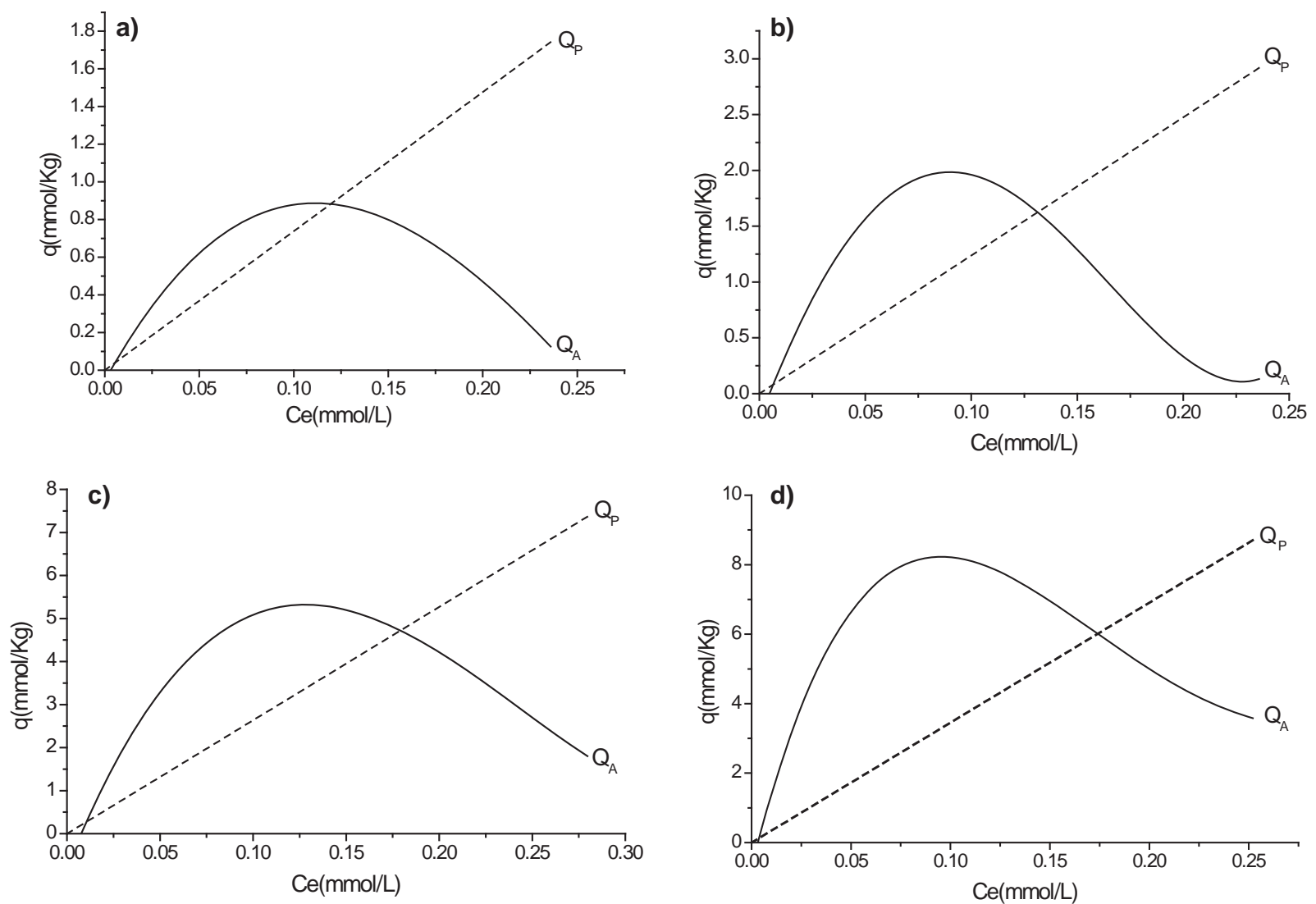

Figure 8. Comparisons of the partition and adsorption contributions to the total sorption amount of atrazine on $Z_{1}-H D T M A$ (a); $Z_{1}$ BODA (b); $C_{B}-$ HDTMA (c) and $C_{B}-B O D A(d) .10 \mathrm{ml}$ atrazine: $100 \mathrm{mg}$ sorbent: agitation time 8, 12, 8, 10 h, respectively: $298 \mathrm{~K}, \mathrm{pH}$ not adjusted.

different behavior. Partition process also increased with increasing the amount of surfactant at the zeolitic surface and clay interlayer.

It is clear from the graphics in Figure 8 that two process take place at the same time (adsorption and partition); however, at low concentration, the superficial adsorption prevail while at higher concentrations the opposite process happens. This is likely due to many superficial free adsorption sites at the beginning of the process. Nevertheless, as the atrazine concentration increase and the absorption sites become occupied, the removal process is connected with the hydrophobic phase of the surfactant by a partition process.

This last observation leads to the conclusion that the removal of atrazine take place on the hydrophobic tails of surfactants regardless of its particular characteristics.

Table 5. Equations for adsorption $\left(Q_{A}\right)$ and partition $\left(Q_{P}\right)$.

\begin{tabular}{lcc}
\hline Sample & Partition $Q_{P}(\mathrm{mmol} / \mathrm{kg})$ & Adsorption $Q_{\mathrm{A}}(\mathrm{mmol} / \mathrm{kg})$ \\
\hline$Z_{1}-$ HDTMA & $7.38 \mathrm{Ce}$ & $0.51 \ln \mathrm{Ce}+2.38-7.38 \mathrm{Ce}$ \\
$Z_{1}-$ BODA & $12.38 \mathrm{Ce}$ & $1.46 \ln \mathrm{Ce}+6.64-12.38 \mathrm{Ce}$ \\
$C_{B}$-HDTMA & $26.35 \mathrm{Ce}$ & $4.58 \ln \mathrm{Ce}+18.62-26.35 \mathrm{Ce}$ \\
$C_{B}-$ BODA & $34.53 \mathrm{Ce}$ & $4.07 \ln \mathrm{Ce}+20.43-34.53 \mathrm{Ce}$ \\
\hline
\end{tabular}

\section{Conclusions}

The length of the surfactant chain is a relevant factor in the formation of a complete or partial mono or bilayer after the modification. It is clear that the coverage of surfactant increased with increasing surfactant chain length and deepens greatly of the ECEC and CEC of the materials. An incomplete bilayer formed in SMC no matter the surfactant applied and an incomplete monolayer in SMZ contrary to previous reports. However, the adsorption capacity of each material is significant. Considering the CMC of the surfactants and linking to the zeolite, external CEC could make the process more efficient reducing reagent quantity.

The material characterization by FTIR was enough to determine the presence of each surfactant on the material and some specific signals related to zeolites and clays.

Classic mathematic models describe a chemical adsorption onto an heterogeneous surface and this statement is in agreement with results found by DXR, where different phases were found in each material.

The atrazine removal is mainly a partition process due to the hydrophobic organic phase formed by surfactants 
tails, which increases with increasing chain length. Therefore it may be concluded that the hydrophobic interaction between the pesticide and aliphatic chains of BODA is more intense than the interaction with HDTMA. Almost all the removal process at high concentration of atrazine depends of the partition process but at lower concentration, it occurs not only by this process but also by absorption process.

\section{Acknowledgement}

The authors extend their appreciation to the Organo Sintesis S.A. de C.V. for providing the surfactant BODA.

\section{Disclosure statement}

No potential conflict of interest was reported by the authors.

\section{References}

[1] Calvert GM. Agricultural pesticide exposure and chronic kidney disease: new findings and more questions. Occup Environ Med. 2016;73(1):1-2.

[2] Wang C, Zhang Z, Yao $\mathrm{H}$, et al. Effects of atrazine and chlorpyrifos on DNA methylation in the liver, kidney and gill of the common carp (Cyprinus carpio L.). Ecotox Environ Safe. 2014;108:142-151.

[3] United States Environmental Protection Agency. Human Health Benchmarks for Pesticides. [cited 2017 Jun 23]. Available from: https://iaspub.epa.gov/apex/pesticides/f? $\mathrm{p}=$ HHBP:home:7862150895069

[4] Liu J. Atrazine. In: Philip W., Encyclopedia of toxicology; 336-338. Amsterdam: Elsevier; 2014.

[5] Köck-Schulmeyer M, Ginebreda A, Postigo C, et al. Fouryear advanced monitoring program of polar pesticides in groundwater of Catalonia (NE-Spain). Sci Total Environ. 2014;470-471:1087-1098.

[6] Hansen AM, Treviño-Quintanilla LG, Márquez-Pacheco H, et al. Atrazina: Un herbicida polémico. Int Contam Ambie. 2013;29:65-84.

[7] Bessac F, Hoyau S. Pesticide interaction with environmentally important cations: a theoretical study of atrazine. Comput Theor Chem. 2011;966:284-298.

[8] Walters JL, Lansdell TA, Lookingland KJ, et al. The effects of gestational and chronic atrazine exposure on motor behaviors and striatal dopamine in male Sprague-Dawley rats. Toxicol Appl Pharmacol. 2015;289(2):185-192.

[9] Wang Y, An X, Shen W, et al. Individual and combined toxic effects of herbicide atrazine and three insecticides on the earthworm, Eisenia fetida. Ecotoxicology. 2016;25 (5):991-999.

[10] Loughlin CM, Canossa IS, Silveyra GR, et al. Effects of atrazine on growth and sex differentiation, in juveniles of the freshwater crayfish Cherax quadricarinatus. Ecotoxicol Environ Saf. 2016;131:96-103.

[11] Xing H, Liu T, Zhang Z, et al. Acute and subchronic toxic effects of atrazine and chlorpyrifos on common carp (Cyprinus carpio L.): Immunotoxicity assessments. Fish Shellfish Immunol. 2015;45(2):327-333.
[12] Bai X, Sun C, Xie J, et al. Effects of atrazine on photosynthesis and defense response and the underlying mechanisms in Phaeodactylum tricornutum. Environ Sci Pollut Res. 2015;22(22):17499-17507.

[13] Proia L, Osorio V, Soley S, et al. Effects of pesticides and pharmaceuticals on biofilms in a highly impacted river. Environ Pollut. 2013;178:220-228.

[14] Baghapour MA, Nasseri S, Derakhshan Z. Atrazine removal from aqueous solutions using submerged biological aerated filter. J Environ Health Sci Eng. 2013;11:1-9.

[15] Luis P, Saquib M, Vinckier C, et al. Effect of membrane filtration on ozonation efficiency for removal of atrazine from surface. Ind Eng Chem Res. 2011;50:8686-8692.

[16] Pathak RK, Dikshit AK. Various techniques for atrazine removal. International Conference on Life Science and Technology 2011;3:19-22.

[17] Abu-Zreig M, Rudra RP, Dickinson WT, et al. Effect of surfactants on sorption of atrazine by soil. J Contam Hydrol. 1999;36:249-263.

[18] Schütz T, Dolinská S, Mockovčiaková A. Characterization of bentonite modified by manganese oxides. Univers J Geosci. 2013;1(2):114-119.

[19] The James Hutton Institute. 2011. Clays and minerals. [cited 2016 Aug 26]. Available from: http://www. claysandminerals.com/minerals/clayminerals

[20] Uzunova EL, Mikosch H. Adsorption of phosphates and phosphoric acid in zeolite clinoptilolite: electronic structure study. Microporous Mesoporous Mat. 2016;232:119125.

[21] Tomsk State University. 2006. Atomic Scale Design Network. [cited 2016 Aug 26]. Available from: http:// asdn.net/asdn/chemistry/zeolites.php

[22] Thanhmingliana DT. Efficient use of hybrid materials in the remediation of aquatic environment contaminated with micro-pollutant diclofenac sodium. Chem Eng J. 2015;263:364-373.

[23] Boujelben N, Gharab S, Bouhamed F, et al. Removal of copper from aqueous solution using tunisian clay. Am J Environ Sci. 2015;11(2):90-98.

[24] Hernández-Montoya V, Pérez-Cruz MA, Mendoza-Castillo $\mathrm{Dl}$, et al. Competitive adsorption of dyes and heavy metals on zeolitic structures. J Environ Manag. 2013;116:213-221.

[25] Saadat M, Nezamzadeh-Ejhieh A. Nanoparticles containing HDTMA and Arsenazo III as a sensitive carbon paste electrode modifier for indirect voltammetric measurement of cesium ions. Electrochim Acta. 2016;217;163-170.

[26] Singhal RK. Materials: to revolutionize decontamination of groundwater from various micro pollutants including Radionuclides. J Environ Anal Chem. 2015;2(1):1-2.

[27] Nezamzadeh-Ejhieh A, Mirzaeyan E. Hexadecylpyridinium surfactant modified zeolite $A$ as an activecomponent of a polymeric membrane sulfite selective electrode. Mater Sci Eng C. 2013;33:4751-4758.

[28] Dutta A, Singh N. Surfactant-modified bentonite clays: preparation, characterization, and atrazine removal. Environ Sci Pollut Res. 2015;22(5):3876-3885.

[29] Jamil TS, Gad-Allah TA, Ibrahim HS, et al. Adsorption and isothermal models of atrazine by zeolite prepared from Egyptian kaolin. Solid State Sci. 2011;13(1):198-203.

[30] Xie Q, Xie J, Wang Z, et al. Adsorption of organic pollutants by surfactant modified zeolite as controlled by surfactant 
chain length. Microporous Mesoporous Mat. 2013;179: 144-150.

[31] Rožić M, Ivanec D, Sekovanić L, et al. Sorption phenomena of modification of clinoptilolite tuffs by surfactant cations. J Colloid Interface Sci. 2009;331(2):295-301.

[32] Lien EJ. Effect of chain length on critical micelle formation and protein binding of quaternary ammonium compounds. J Med Chem. 1976;19(6):849-850.

[33] Yukselen Y, Kaya A. Suitability of the methylene blue test for surface area, cation exchange capacity and swell potential determination of clayey soils. Eng Geol. 2008;102(1-2):38-45.

[34] Toledo-Jaldin HP. Remoción de atrazina con una zeolita tipo clinoptilolita modificada con HDTMA. Toluca: Instituto Tecnológico de Toluca; 2015.

[35] Díaz-Nava MC, Olguín MT, Solache-Ríos $M$, et al. Characterization and improvement of ion exchange capacities of Mexican clinoptilolite-rich tuffs. J Incl Phenom Macrocycl Chem. 2005;51(3):231-240.

[36] Gładysz-Płaska A, Majdan M, Pikus S. Simultaneous adsorption of chromium( $\mathrm{VI})$ and phenol on natural red clay modified by HDTMA. Chem Eng J. 2012;179:140-150.

[37] Anari-Anaraki M, Nezamzadeh-Ejhieh A. Modification of an Iranian clinoptilolite nano-particles by hexadecyltrimethyl ammonium cationic surfactant and dithizone for removal of $\mathrm{Pb}$ (II) from aqueous solution. J Colloid Interface Sci. 2015;440:272-281.

[38] Simonin JP, Boute J. Intraparticle diffusion-adsorption model to describe liquid/solid adsoption kinetics. Rev Mex Ing Quím. 2016;15(1):161-173.

[39] Chi KL, Hui HB, Chin HN, et al. Application of zeolite-activated carbon macrocomposite for the adsorption of acid orange 7: isotherm, kinetic and thermodynamic studies. Environ Sci Pollut Res. 2013;20:7243-7255.

[40] Krajišnik D, Daković A, Milojević $M$, et al. Properties of diclofenac sodium sorption onto natural zeolite modified with cetylpyridinium chloride. Colloid Surf B-Biointerfaces. 2011;83:165-172.

[41] Malekian R, Abedi-Koupai J, Eslamian SS. Influences of clinoptilolite and surfactant-modified clinoptilolite zeolite on nitrate leaching and plant growth. J Hazard Mater. 2011;185:970-976.

[42] Jarraya I, Fourmentin S, Benzina M, et al. VOC adsorption on raw and modified clay materials. Chem Geol. 2010;275:1-8.

[43] Zheng S, Sun Z, Park Y, et al. Removal of bisphenol A from wastewater by Ca-montmorillonite modified with selected surfactants. Chem Eng J. 2013;234:416-422.

[44] Jović-Jovičić NP, Milutinović-Nikolić AD, Žunić MJ, et al. Synergic adsorption of $\mathrm{Pb}^{2+}$ and reactive dye-RB5 on two series of organomodified bentonites. J Contam Hydrol. 2013;150:1-11.

[45] Hoseini Z, Nezamzadeh-Ejhieh A. An oxalate selective electrode based on modified PVC-membrane with tetrabutylammonium - Clinoptilolite nanoparticles. Mater Sci Eng C. 2013;33:4751-4758.

[46] Nezamzadeh-Ejhieh A, Tavakoli-Ghinani S. Effect of a nano-sized natural clinoptilolite modified by the hexadecyltrimethyl ammonium surfactant on cephalexin drug delivery. Comptes Rendus Chimie. 2014;17:49-61.

[47] Naghash A, Nezamzadeh- Ejhieh A. Comparison of the efficiency of modified clinoptilolite with HDTMA and
HDP surfactants for the removal of phosphate in aqueous solutions. J Ind Eng Chem. 2015;31:185-191.

[48] Majdan M, Maryuk O, Gładysz-Płaska A, et al. Spectral characteristics of the bentonite loaded with benzyldimethyloctadecylammonium chloride, hexadecyltrimethylammonium bromide and dimethyldioctadecylammonium bromide. J Mol Struct. 2008;874:101-107.

[49] Li Z, Gallus L. Adsorption of dodecyl trimethylammonium and hexadecyl trimethylammonium onto kaolinite-competitive adsorption and chain length effect. Appl Clay Sci. 2007;35(3):250-257.

[50] Taffarel SR, Rubio J. Adsorption of sodium dodecyl benzene sulfonate from aqueous solution using a modified natural zeolite with CTAB. Miner Eng. 2010;23:771779.

[51] Nezamzadeh-Ejhieh A, Afshari E. Modification of a PVCmembrane electrode by surfactant modified clinoptilolite zeolite towards potentiometric determination of sulfide. Micropor Mesopor Mater. 2012;153:267-274.

[52] Barczyk K, Mozgawa W, Król M. Studies of anions sorption on natural zeolites. Spectrochim. Acta, Part A. Volumen 2014;133:876-882.

[53] Sharafzadeh S, Nezamzadeh-Ejhieh A. Using of anionic adsorption property of a surfactant modified clinoptilolite nano-particles in modification of carbon paste electrode as effective ingredient for determination of anionic ascorbic acid species in presence of cationic dopamine species. Electrochim Acta. 2015;184:371-380.

[54] Liu N, Charrua AB, Chih-Huang W, et al. Characterization of biochars derived from agriculture wastes and their adsorptive removal of atrazine from aqueous solution: a comparative study. Bioresour Technol. 2015;198:55-62.

[55] Blanco-Flores A, Colín-Cruz A, Gutiérrez-Segura E, et al. Efficient removal of crystal violet dye from aqueous solutions by vitreous tuff mineral. Environ Technol. 2014;35:1508-1519.

[56] Vidal BC, Raulino GC, Barros LA, et al. BTEX removal from aqueous solutions by HDTMA-modified $\mathrm{Y}$ zeolite. J Environ Manage. 2012;112:178-185.

[57] Tarek SJ, Tarek AG, Hanan SI, et al. Adsorption and isothermal models of atrazine by zeolite prepared from Egyptian kaolin. Solid State Sci. 2011;13:198-203.

[58] Chen X. Modeling of experimental adsorption isotherm data. Information. 2015;6:14-22.

[59] Chingombe P, Saha B, Wakeman RJ. Sorption of atrazine on conventional and surface modified activated carbons. J Colloid Interface Sci. 2006;302:408-416.

[60] Neitsch SL, Mclnnes KJ, Senseman SA, et al. Melaminebased organoclay to sequester atrazine. Chemosphere. 2006;64:704-710.

[61] Lladó J, Lao-Luque C, Ruiz B, et al. Role of activated carbon properties in atrazine and paracetamol adsorption equilibrium and kinetics. Process Saf Environ Prot. 2015;95:51-59.

[62] Salvestrini S, Sagliano P, lovino P, et al. Atrazine adsorption by acid-activated zeolite-rich tuffs. Appl Clay Sci. 2010;49:330-335.

[63] Kovaios ID, Paraskeva CA, Koutsoukos PG. Adsorption of atrazine from aqueous electrolyte solutions on humic acid and silica. J Colloid Interface Sci. 2011;356:277-285.

[64] Mandal A, Singh N. Kinetic and isotherm error optimization studies for adsorption of atrazine and imidacloprid 
on bark of Eucalyptus tereticornis L. J Environ Sci Health B. 2016;51:192-203.

[65] Zhu L, Chen B, Shen X. Sorption of phenol, p-nitrophenol, and aniline to dual-cation organobentonites from water. Environ Sci Technol. 2000;34:2997-3002.

[66] Lamarque A, Zygadlo J, Labuckas D, et al. Fundamentos teóricos y prácticos de química orgánica. 1st ed. Córdoba: Encuentro; 2008.
[67] Batu V. Applied flow and solute transport modeling in aquifers: fundamental principles and analytical and numerical methods. Boca Raton: Taylor and Francis; 2006.

[68] Rojas R, Morillo J, Usero J, et al. Enhancing soil sorption capacity of an agricultural soil by addition of three different organic wastes. Sci Total Environ. 2013;32:614623. 